\title{
Mechanism and treatment of hypertriglyceridaemia in gout
}

\author{
T. GIBSON, K. KILBOURN, I. HORNER, AND H. A. SIMMONDS \\ From the Guy's Arthritis Research Unit and Department of Medicine, Guy's Hospital Medical School, London
}

SUMMARY Using the Intralipid lipid tolerance test we could not demonstrate any direct effect of serum triglyceride on uric acid or any influence of hyperuricaemia on triglyceride removal. This result supports previous studies suggesting that hyperuricaemia and hypertriglyceridaemia are linked through the association of obesity and alcohol excess rather than a direct cause and effect mechanism. It was possible to demonstrate significant reductions of serum triglyceride in patients with gout by reducing either their alcohol intake or body weight. Reduction of serum uric acid by probenecid had no effect on serum triglyceride or cholesterol. Similarly, allopurinol had no significant effect on serum triglyceriide, but a significant fall of serum cholesterol was observed.

Considerable evidence now exists to support an association between gout and hypertriglyceridaemia (Feldman and Wallace, 1964; Darlington and Scott, 1972). We have previously suggested that this relationship exists because obesity and excessive alcohol consumption are common associates of both hypertriglyceridaemia and gout (Gibson and Grahame, 1974). Other studies have failed to implicate obesity in this way (Emmerson and Knowles, 1971), and a recent review has concluded that, although obesity may contribute to hypertriglyceridaemia in gout, it is unlikely to be the sole factor (Scott, 1977). Whether alcohol abuse is an additional cause which with obesity is sufficient to explain the phenomenon entirely remains controversial. Few studies have examined their independent contributions to hyperuricaemia and hypertriglyceridaemia simultaneously, and there is a common assumption that uric acid and triglyceride are linked by some alternative and fundamental metabolic mechanism (Mielants et al., 1973). In favour of this view is the reported concurrence of gout and elevated serum triglyceride levels in an isolated family (Bennett et al., 1973), the occasional reduction of serum triglyceride and enhanced triglyceride removal during allopurinol therapy (Bluestone et al., 1971), and the shared hypolipidaemic and uricosuric properties of both clofibrate (Trevaks and Lovell, 1965) and halofenate (Aronow et al., 1973).

Accepted for publication 13 March 1978

Correspondence to Dr T. Gibson, Guy's Arthritis Research Unit, Guy's Hospital Medical School, London SE1 9RT.
The questions and therapeutic implications posed by these observations have prompted us to explore the relationship further by examining the influence of an exogenous triglyceride load on blood uric acid, the response of serum triglyceride during the drug treatment of hyperuricaemia, and the effects of alcohol restriction and weight reduction on serum uric acid and lipids.

\section{Materials and methods}

(1) Four hyperuricaemic subjects (mean age 50; mean weight $71 \mathrm{~kg}$ ) and 6 patients with noninflammatory musculoskeletal disorders (mean age 53 ; mean weight $61 \mathrm{~kg}$ ) and normal blood uric acid levels received intravenous Intralipid $1 \mathrm{ml} / \mathrm{kg}$ body weight after an overnight fast. All subjects had normal fasting serum triglyceride levels. The Intralipid (experimental batch No. 199523) was injected as a bolus over a 2-minute period. Plasma triglyceride and serum uric acid were measured at regular intervals for 120 minutes. The circulating Intralipid triglyceride was estimated by nephelometry using plasma diluted to $1: 50$ with $0.9 \%$ saline as in the intravenous lipid tolerance test described by Lewis et al. (1972).

(2) Twenty-five male patients with a history of gout (mean age 58) were given either allopurinol $200 \mathrm{mg}$ daily or probenecid $1.0 \mathrm{~g}$ daily for 4 weeks. The treatments were randomly allocated. None of the patients had received blood uric acid lowering agents during the preceding month. No restrictions were 
placed on their dietary habits. Venous blood samples were obtained after an overnight fast for blood uric acid, cholesterol, and triglyceride before and on completing the treatment periods.

(3) Twelve gouty males (mean age 48) who drank 3 or 4 pints $\left(1 \frac{1}{2}-21\right)$ of beer daily agreed to restrict or eliminate their alcohol consumption for 2 weeks. None had received drug treatment for hyperuricaemia during the 2 weeks preceding the study. The patients were encouraged to maintain their normal food intake as far as possible. Fasting blood samples for uric acid and lipids were obtained before and after alcohol abstention.

(4) Eleven obese patients with gout (mean age 49) who had received no blood uric acid lowering drugs for 2 weeks underwent a period of weight reduction over periods of 4 to 8 weeks. Each received written instructions about high calorie foods to be avoided, but all were requested to maintain normal alcohol consumption. Fasting blood uric acid, triglyceride, and cholesterol were estimated before and after the above experimental periods by the respective methods of Simmonds (1967), Cramp and Robertson (1968), and Levine and Zak (1964). Results were compared by Student's $t$ test.

\section{Results}

Intravenous Intralipid had no effect on blood uric acid levels (Table 1). Intralipid triglyceride was cleared rapidly from the circulation, reaching a mean peak of $135 \mathrm{mg} / 100 \mathrm{ml}(1.52 \mathrm{mmol} / \mathrm{l})$ above the fasting level. The half life $\left(\mathrm{T} \frac{1}{2}\right) \pm \mathrm{SD}$ of the serum triglyceride in the 4 hyperuricaemic patients was $16 \cdot 4 \pm 4 \cdot 2 \mathrm{~min}$ and in the normouricaemic subjects was $16.06 \pm 2.03$ min (Fig. 1).

The results of the other three studies are outlined in Table 2.

Both allopurinol and probenecid exerted their expected effect on blood uric acid. Neither induced a significant reduction of serum triglyceride, but in 10 of the 14 subjects receiving allopurinol values did decline slightly. Of those receiving probenecid

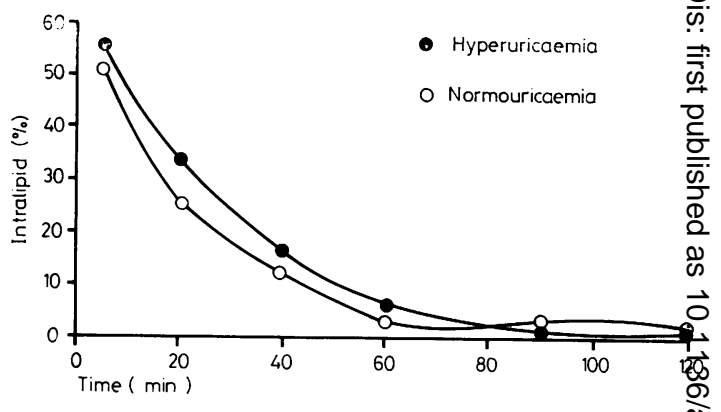

Fig. 1 Intravenous Intralipid clearance in hyperuricaemic and normouricaemic subjects.

minor reductions of serum triglyceride occurred in Serum cholesterol levels fell in 10 patients receiving allopurinol, and the difference in mean values reached statistical significance $(t=2 \cdot 37 ; \mathrm{P}<0 \cdot 05)$. These changes were unassociated with any change of bod weight. By contrast, the mean value of cholester was unaltered by probenecid.

Alcohol restriction or abstention was achieved by 12 subjects for 2 weeks. Their normal average daify consumption was 5 pints $\left(2 \frac{1}{2} 1\right)$ of beer, but since the study was conducted on an outpatient basis no attempt was made to gauge the precise diminutio of intake. Striking and significant reductions of serum uric acid and triglyceride were observeg (Fig. 2). A modest but insignificant fall of serum cholesterol was also seen. Three patients lost betwee 2 and $4 \mathrm{~kg}$ body weight during the experiment, but mean values did not differ significantly (Table 2 Evaluation of the 9 patients whose body weighis remained constant $(77 \pm 13.4 \mathrm{~kg}$ before and 77.8 $\pm 13.5 \mathrm{~kg}$ after alcohol restriction) revealed a still significant reduction of mean serum uric acid from $8 \cdot 31 \pm 0.7 \mathrm{mg} / 100 \mathrm{ml}(0 \cdot 50 \pm 0.04 \mathrm{mmol} / \mathrm{l})$ to $7 \cdot 2 \pm 0.33 \mathrm{mg} / 100 \mathrm{ml}(0.39 \pm 0.01 \mathrm{mmol} / \mathrm{h}$ $(t=3 \cdot 77 ; \mathrm{P}<0 \cdot 01)$. Serum triglyceride fell from $269 \pm 166 \mathrm{mg} / 100 \mathrm{ml}(3.03 \pm 1.87 \mathrm{mmol} / \mathrm{l})$ to $168 \pm 52 \mathrm{mg} / 100 \mathrm{ml}(1 \cdot 89 \pm 0 \cdot 58 \mathrm{mmol} / \mathrm{l})\left(t \frac{\mathrm{T}}{\mathrm{O}}\right.$ $2 \cdot 61 ; \mathrm{P}<0 \cdot 05)$.

Table 1 Effect of intravenous Intralipid on mean serum uric acid $( \pm \mathrm{SD})$ in hyperuricaemic and normouricaemic patients

\begin{tabular}{|c|c|c|c|c|c|c|c|c|}
\hline Time (min) & & 0 & 5 & 20 & 40 & 60 & 90 & 120 \\
\hline \multirow[t]{2}{*}{$\begin{array}{l}\text { Hyper- } \\
\text { uricaemia }\end{array}$} & $\begin{array}{l}\text { Serum uric } \\
\text { acid } \mathrm{mg} / 100 \mathrm{ml} \\
(\mathrm{mmol} / \mathrm{l})\end{array}$ & $\begin{array}{l}7.8 \pm 1.44 \\
(0.46 \pm 0.08)\end{array}$ & & $\begin{array}{l}8.0 \pm 1.25 \\
(0.47 \pm 0.07)\end{array}$ & $\begin{array}{l}8.0 \pm 1.0 \\
(0.47 \pm 0.06)\end{array}$ & $\begin{array}{l}7.8 \pm 1.1 \\
(0.46 \pm 0.06)\end{array}$ & $\begin{array}{l}7.8 \pm 1.0 \\
(0.46 \pm 0.06)\end{array}$ & $\begin{array}{l}7.9 \pm 1.0 \\
(0.47 \pm 0.0\end{array}$ \\
\hline & Intralipid (\%) & - & $56 \pm 18$ & $34 \pm 14$ & $16 \pm 9$ & $6 \pm 5$ & $2 \cdot 0 \pm 1 \cdot 8$ & 0 \\
\hline \multirow[t]{2}{*}{$\begin{array}{l}\text { Normo- } \\
\text { uricaemia }\end{array}$} & $\begin{array}{l}\text { Serum uric } \\
\text { acid } \mathrm{mg} / 100 \mathrm{ml} \\
(\mathrm{mmol} / \mathrm{l})\end{array}$ & $\begin{array}{l}5.4 \pm 0.5 \\
(0.32 \pm 0.03)\end{array}$ & & $\begin{array}{l}5 \cdot 0 \pm 1 \cdot 0 \\
(0.3 \pm 0.06)\end{array}$ & $\begin{array}{l}5 \cdot 2 \pm 1 \cdot 2 \\
(0.31 \pm 0.08)\end{array}$ & $\begin{array}{l}5 \cdot 0 \pm 1 \cdot 4 \\
(0.3 \pm 0.08)\end{array}$ & $\begin{array}{l}5.4 \pm 1.1 \\
(0.32 \pm 0.06)\end{array}$ & $\begin{array}{l}5 \cdot 1 \pm 1 \cdot 1 \\
(0.3 \pm 0.06\end{array}$ \\
\hline & Intralipid (\%) & - & $51 \pm 9$ & $25 \pm 10$ & $14 \pm 4$ & $3 \pm 3$ & $4 \pm 2$ & $1.0 \pm 0.5$ \\
\hline
\end{tabular}


Table 2 Influence of allopurinol, probenecid, alcohol restriction, and weight reduction on mean $( \pm S D)$ fasting serum uric acid, triglyceride, and cholesterol ( $n=$ number of observations)

\begin{tabular}{|c|c|c|c|c|}
\hline & $\begin{array}{l}\text { Body weight } \\
\text { kg }\end{array}$ & $\begin{array}{l}\text { Serum uric acid } \\
\mathrm{mg} / 100 \mathrm{ml}(\mathrm{mmol} / \mathrm{l})\end{array}$ & $\begin{array}{l}\text { Serum triglyceride } \\
\mathrm{mg} / 100 \mathrm{ml}(\mathrm{mmol} / \mathrm{l})\end{array}$ & $\begin{array}{l}\text { Serum cholesterol } \\
\mathrm{mg} / 100 \mathrm{ml}(\mathrm{mmol} / \mathrm{l})\end{array}$ \\
\hline $\begin{array}{l}\text { Allopurinol } \\
t \\
\mathbf{P}\end{array}$ & $\begin{array}{l}82 \cdot 3 \pm 15 \cdot 8 \\
82 \cdot 0 \pm 15 \cdot 6 \\
0 \cdot 97(n=14) \\
\text { NS }\end{array}$ & $\begin{array}{l}8.57 \pm 1.45(0.5 \pm 0.08) \\
6.3 \pm 0.75(0.37 \pm 0.04) \\
5.69(\mathrm{n}=13) \\
<0.001\end{array}$ & $\begin{array}{l}142 \pm 107(1.6 \pm 1 \cdot 2) \\
125 \pm 69(1.41 \pm 0.77) \\
1.66(n=14) \\
\text { NS }\end{array}$ & $\begin{array}{l}243 \pm 50(6 \cdot 3 \pm 1 \cdot 3) \\
224 \pm 40(5 \cdot 8 \pm 1 \cdot 0) \\
2 \cdot 37(n=14) \\
<0.05\end{array}$ \\
\hline $\begin{array}{l}\text { Probenecid } \\
t \\
\mathrm{P}\end{array}$ & $\begin{array}{l}79 \cdot 3 \pm 14 \cdot 5 \\
79 \cdot 5 \pm 14 \cdot 8 \\
0 \cdot 9(\mathrm{n}=11) \\
\text { NS }\end{array}$ & $\begin{array}{l}7.98 \pm 1.33(0.47 \pm 0.07) \\
5.57 \pm 1.17(0.33 \pm 0.06) \\
8.96(\mathrm{n}=11) \\
<0.001\end{array}$ & $\begin{array}{l}134 \pm 48(1.5 \pm 0.54) \\
146 \pm 57(1.64 \pm 0.64) \\
1.37(n=11) \\
\text { NS }\end{array}$ & $\begin{array}{c}240 \pm 24(6 \cdot 2 \pm 0 \cdot 64) \\
251 \pm 44(6 \cdot 5 \pm 1 \cdot 13) \\
1 \cdot 07(n=11) \\
\text { NS }\end{array}$ \\
\hline $\begin{array}{l}\text { Alcohol } \\
\text { restriction } \\
\text { t } \\
\mathbf{P}\end{array}$ & $\begin{array}{l}81 \cdot 6 \pm 13 \cdot 4 \\
81 \cdot 0 \pm 12 \cdot 5 \\
1 \cdot 45(\mathrm{n}=11) \\
\text { NS }\end{array}$ & $\begin{array}{l}8.5 \pm 1 \cdot 1(0.48 \pm 0.07) \\
7.3 \pm 0.76(0.43 \pm 0.04) \\
6.4(n=12) \\
<0.001\end{array}$ & $\begin{array}{l}248 \pm 159(2.8 \pm 1.8) \\
147 \pm 51(1.66 \pm 0.57) \\
2.66(n=12) \\
<0.025\end{array}$ & $\begin{array}{l}251 \pm 42(6 \cdot 5 \pm 1 \cdot 1) \\
213 \pm 57(5 \cdot 5 \pm 1 \cdot 5) \\
1 \cdot 9(\mathrm{n}=12) \\
\quad \mathrm{NS}\end{array}$ \\
\hline $\begin{array}{l}\text { Weight } \\
\text { reduction } \\
t \\
\mathbf{P}\end{array}$ & $\begin{array}{l}83 \cdot 3 \pm 9.4 \\
78.4 \pm 10 \\
5 \cdot 27(\mathrm{n}=11) \\
<0 \cdot 001\end{array}$ & $\begin{array}{l}7 \cdot 8 \pm 1.42(0.46 \pm 0.08) \\
6 \cdot 7 \pm 1 \cdot 3(0.39 \pm 0.07) \\
2 \cdot 1(\mathrm{n}=11) \\
\quad \mathrm{NS}\end{array}$ & $\begin{array}{l}237 \pm 156(2 \cdot 7 \pm 1 \cdot 76) \\
150 \pm 75(1 \cdot 7 \pm 0.84) \\
2 \cdot 31(\mathrm{n}=11) \\
<0.05\end{array}$ & $\begin{array}{l}255 \pm 34(6.6 \pm 0.9) \\
256 \pm 44(6.6 \pm 1 \cdot 1) \\
0.22(n=11) \\
\quad \text { NS }\end{array}$ \\
\hline
\end{tabular}

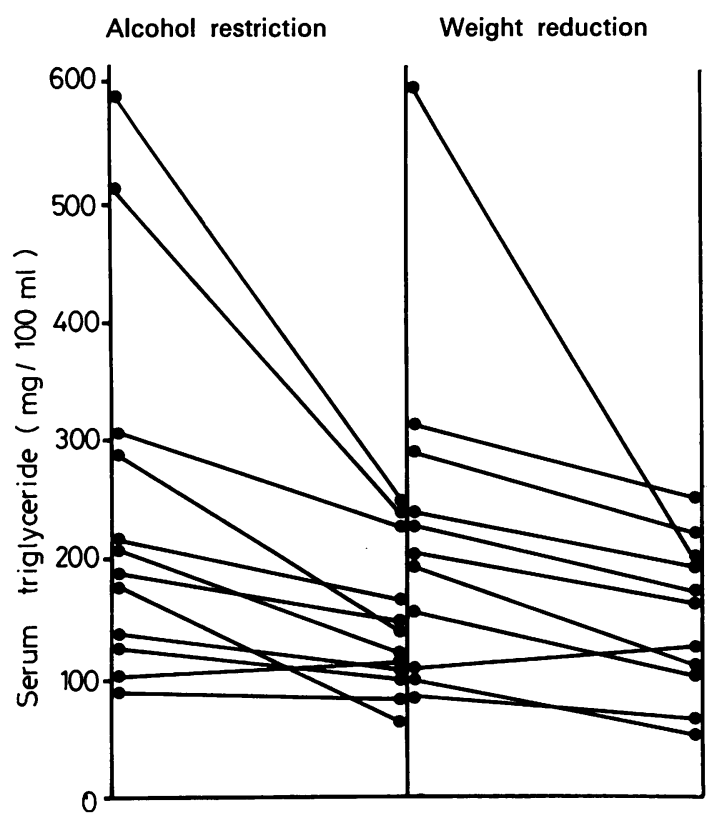

Fig. 2 Effect of alcohol restriction and weight reduction on individual fasting serum triglyceride levels.

Significant weight loss in 11 patients resulted in falls of serum uric acid and triglyceride but not cholesterol (Table 1). The decline of the mean uric acid value just failed to reach the conventional level of statistical significance $(t=2 \cdot 1 ; \mathrm{P}<0 \cdot 1)$. Serum triglyceride was reduced significantly, and the magnitude of individual changes was similar to that obtained by alcohol restriction (Fig. 2 and Table 2).

\section{Discussion}

The possibility that circulating triglyceride may exert a direct effect on blood uric acids levels needs to be entertained, particularly since some drugs introduced as lipid lowering agents may also possess hypouricaemic properties (Trevaks and Lovell, 1965; Aronow et al., 1973). We were unable to demonstrate such an effect when triglyceride levels were artificially raised by injection of Intralipid fat emulsion. Arguably, prolonged infusion of Intralipid would have better simulated clinical hyperlipidaemia, but resultant ketosis would have induced renal retention of uric acid and complicated interpretation of the results. Others have shown that elevation of blood uric acid seen during infusions of several hours is slight and is abolished by correction of ketosis (Elkeles and Chalmers, 1977).

The clearance rate of Intralipid triglyceride has an indirect and hyperbolic relationship with the level of fasting serum triglyceride (Lewis et al., 1972). Defects of triglyceride removal demonstrated by this test may contribute to hypertriglyceridaemia (Boberg et al., 1969) and the variable fall of fasting triglyceride reported by Bluestone et al. (1971) during allopurinol treatment was associated with an increased fractional turnover of Intralipid triglyceride. In our study clearance of Intralipid was identical in patients with and without hyperuricaemia, suggesting that blood uric acid levels do not directly influence triglyceride removal. In an analogous study using the Intralipid tolerance test it was not possible to demonstrate any direct effect of triglyceride on glucose tolerance or of glucose on triglyceride removal (Gibson et al., 1974). These investigations 
support the view that hyperuricaemia, like carbohydrate intolerance, is linked to hypertriglyceridaemia by shared factors rather than by a cause and effect mechanism.

Reduction of blood uric acid by 2 drugs with dissimilar modes of action failed to exert any significant effect on fasting triglyceride levels. In a majority of patients receiving allopurinol, triglyceride levels showed a downward trend. This finding was similar to that observed by Bluestone et al. (1971). The lack of any consistent effect suggests that uric acid metabolism is not invariably and intimately bound to that of triglyceride. It is possible that more prolonged periods of treatment may influence triglyceride levels significantly, and further studies are awaited. The effect of allopurinol on cholesterol has not, to our knowledge, been previously documented. The observation merits closer evaluation in a larger group of patients before its significance can be fully determined.

The association of both hyperuricaemia and hypertriglyceridaemia with alcohol excess is well recognised, but the mechanisms are disputed. The best established explanation for the elevation of blood uric acid following alcohol consumption is that urate clearance is reduced by a rise in blood lactate (Lieber et al., 1962). However, there is equally convincing, though less frequently quoted evidence that alcohol exerts an effect by increasing uric acid production (Delbarre et al., 1967). This view is in accord with our own experience (unpublished observations).

There is similar uncertainty about the mechanism by which alcohol may influence serum triglyceride. The increased esterification of free fatty acids in man (Nestel and Hirsch, 1965) and the increased synthesis of lipoproteins in rats (Baraona and Lieber, 1970) argue in favour of accelerated triglyceride production. However, Losowsky et al. (1963) have suggested that reduced lipoprotein lipase activity may impair lipid removal from the circulation. Even modest doses of alcohol will cause a consistent rise of serum triglyceride (Taskinen and Nikkila, 1977), but the magnitude and duration of response may be related to pre-existing lipoprotein disorder or other factors (Mendelson and Mello, 1973). This might explain why a wide range of fasting triglyceride levels was seen in our patients whose daily alcohol consumption, although excessive, did not differ much between subjects. Nevertheless, our results clearly demonstrated that alcohol abstention has a marked effect on serum triglyceride in gouty patients. The fall in fasting triglyceride was consistent, and greater in those with a higher initial degree of elevation. It could not be explained on the basis of weight reduction alone. The results were remarkably similar to those achieved by Chait et al. (1972) in non-gouty hypertriglyceridaemic subjects. The concomitant falṭ. in serum uric acid following alcohol restriction wa significant and similar to that previously noted? following alcohol withdrawal (Lieber et al., 1962)은

Recent univeariate analysis of several thousand men has confirmed a correlation between body weight, obesity, and serum uric acid (Yano et al. $\$$ 1977). The same study showed that serum trigly» ceride was correlated with obesity with almost equab significance. The mechanisms linking hyperuri: caemia and hypertriglyceridaemia with obesity remain obscure. Urate production may be increase and urate renal clearance reduced by obesity (Emmer son, 1973). A significant fall in blood uric acid whickiw was correlated with the extent of weight loss has been reported by Nicholls and Scott (1972), but there wasis no consistent change of uric acid production as measured by urine uric acid excretion or of urate clearance. The hypertriglyceridaemia of obesity, might be explained on the basis of insulin resistance hyperinsulinaemia and subsequent acceleratec hepatic triglyceride production (Kral et al., 1977) Whatever the biochemical sequence, weight reduction is undoubtedly one effective approach to the treat-cै ment of hypertriglyceridaemia (Olefsky et al., 1974): especially when combined with careful counselling (Gotto et al., 1977).

The dual effect of weight loss on serum uric aciकू and triglyceride has been previously documentec by Scott and Sturge (1977) and Elkeles (1976). Botlp these studies also reported significant reductions o $\overrightarrow{\vec{b}}$ serum cholesterol, an observation we failed to confirm. Obesity may well influence serum chol? esterol adversely, but the association seems less. pronounced than that with hypertriglyceridaemiæ (Bray et al., 1976). The difference between our results and those obtained by Scott and Sturge $(1977)$ and Elkeles (1976) cannot be readily explained The average initial weight of the patients and the response of body weight to diet was similar in al $\bar{b}$ 3 studies.

The clinical implications of hypertriglyceridaemis remain controversial, and recent studies have reached. conclusions as disparate as their forerunners. An increased risk of ischaemic heart disease has been convincingly demonstrated by Pelkonen et al. (1977) but Gordon et al. (1977) have claimed that the risk is slight and confined to women. It would neverthe less seem prudent to investigate the possibility of hypertriglyceridaemia in all gouty and hyperurien caemic patients. We have shown that orthodox dietary measures can have a marked influence on serum triglyceride levels in gout, and the same diet $\vec{D}$ ary amendments may also reduce serum uric acid $\frac{?}{\mathbb{D}}$ Our earlier study (Gibson and Grahame, 1974) suggested that obesity, alcohol excess, or both are 
the main causes of hypertriglyceridaemia in gout, and our subsequent experience has failed to isolate more than the occasional patient whose elevated triglyceride cannot be explained on this basis. The results of the current study do not suggest a more direct influence of serum uric acid on triglyceride or vice versa. We would therefore advocate that gouty patients with hypertriglyceridaemia should be given dietary counselling, since hypouricaemic treatment may ameliorate the more obvious disease without regard to the other and perhaps more pernicious sequel of sumptuous dietary habits.

We gratefully acknowledge the financial support of the Arthritis and Rheumatism Council.

\section{References}

Aronow, W. S., Harding, P. R., Khursheed, M., Vangrow, J. S., and Papageorges, N. P. (1973). Effect of halofenate on serum uric acid. Clinical Pharmacology and Therapeutics, 14, 371-373.

Baraona, E., and Lieber, C. S. (1970). Effects of chronic ethanol feeding on serum lipoprotein metabolism in the rat. Journal of Clinical Investigation, 49,769-778.

Bennett, R. M., Chait, A., and Lewis, B. (1973). Familial hyperuricaemia and hypertriglyceridaemia. Annals of the Rheumatic Diseases, 32, 497-500.

Bluestone, R., Lewis, B., and Mervart, I. (1971). Hyperlipoproteinaemia in gout. Annals of the Rheumatic Diseases, 30, 134-137.

Boberg, J., Carlson, L. A., and Hallberg, D. (1969). Application of a new intravenous fat tolerance test in the study of hypertriglyceridaemia in man. Journal of Atherosclerosis Research, 9, 159-169.

Bray, G. A., Dahms, W. T., Greenway, F. L., Marriott, M., Molitch, M., and Atkinson, R. (1976). Evaluation of the obese patient. 2. Clinical findings. Journal of the American Medical Association, 235, 2008-2010.

Chait, A., Mancini, M., February, A. W., and Lewis, B. (1972). Clinical and metabolic study of alcoholic hyperlipidaemia. Lancet, 2, 62-64.

Cramp, D. G., and Robertson, G. (1968). The fluorometric assay of triglyceride by a semiautomated method. Analytical Biochemistry, 25, 246-251.

Darlington, L. G., and Scott, J. T. (1972). Plasma lipid levels in gout. Annals of the Rheumatic Diseases, 31, 487-489.

Delbarre, F., Auscher, C., Brouilhet, H., and de Géry, A. (1967). The effect of alcohol on gout and uric acid metabolism. Semaine des Hôpitaux de Paris, 43, 659-664.

Elkeles, R. S. (1976). The effect of hypolipidaemic therapy on serum uric acid concentration. Atherosclerosis, 24, 587-590.

Elkeles, R. S., and Chalmers, R. A. (1977), Hypertriglyceridaemia and hyperuricaemia. Lancet, 2, 252.

Emmerson, B. T., and Knowles, B. R. (1971). Triglyceride concentrations in primary gout and gout of chronic lead nephropathy. Metabolism, 20, 721-729.

Emmerson, B. T. (1973). Alteration of urate metabolism by weight reduction. Australian and New Zealand Journal of Medicine, 3, 410-412.

Feldman, E. B., and Wallace, S. L. (1964). Hypertriglyceridaemia in gout. Circulation, 29, 508-513.

Gibson, T., Fuller, J. H., Grainger, S. L., Jarrett, R. J., and
Keen, H. (1974). Intralipid triglyceride and oral glucose tolerance. Diabetologia, 10, 97-100.

Gibson, T., and Grahame, R. (1974). Gout and hyperlipidaemia. Annals of the Rheumatic Diseases, 33, 298-303.

Gordon, T., Castelli, W. B., Hjortland, M. C., Kannel, W. P., and Dawber, T. R. (1977). High density lipoprotein as a protective factor against coronary heart disease. The Framingham Study. American Journal of Medicine, 62, 707-714.

Gotto, A. M., De Bakey, M. E., Foreyt, J. P., Scott, L. W., and Thornby, J. I. (1977). Dietary treatment of type IV hyperlipoproteinaemia. Journal of the American Medical Association, 237, 1212-1215.

Kral, J. G., Lundholm, K., Bjorntorp, P., Sjostrom, L., and Schersten, T., (1977). Hepatic lipid metabolism in severe human obesity. Metabolism, 26, 1025-1031.

Levine, J. B., and Zak, B. (1964). Automated determination of serum total cholesterol. Clinica Chimica Acta, 10, 381-4.

Lewis, B., Boberg, J., Mancini, M., and Carlson, L. A. (1972). Determination of the intravenous fat tolerance test with Intralipid by nephelometry. Atherosclerosis, 15, 83-86.

Lieber, C. S. Jones, D. P., Losowsky, M. S., and Davidson, C. S. (1962). Interrelation of uric acid and ethanol metabolism in man. Journal of Clinical Investigation, 41, 18631870.

Losowsky, M. S., Jones, D. P., Davidson, C. S., and Lieber, C. S. (1963). Studies of alcoholic hyperlipidaemia and its mechanism. American Journal of Medicine, 35, 794-803.

Mendelson, J. H., and Mello, N. K. (1973). Alcohol-induced hyperlipidemia and beta-lipoproteins. Science, 180, 13721374.

Mielants, H., Veys, E. M., and de Weerdt, A. (1973). Gout and its relation to lipid metabolism. 1. Serum uric acid, lipid and lipoportein levels in gout. Annals of the Rheumatic Diseases, 32, 501-505.

Nestel, P. J., and Hirsch, E. Z. (1965). Mechanism of alcohol induced hypertriglyceridemia. Journal of Laboratory and Clinical Medicine, 60, 357-365.

Nicholls, A., and Scott, J. T. (1972). Effect of weight-loss on plasma and urinary levels of uric acid. Lancet, 2, 12231224.

Olefsky, J., Reaven, G. M., and Farquar, J. W. (1974). Effects of weight reduction on obesity. Studies of lipid and carbohydrate metabolism in normal and hyperlipoproteinemic subjects. Journal of Clinical Investigation, 53, 64-76.

Pelkonen, R., Nikkila, E. A., Kokinen, S., Penttinen, K., and Sarna, S. (1977). Association of serum lipids and obesity with cardiovascular mortality. British Medical Journal, 2, 1185-1187.

Scott, J. T., and Sturge, R. A. (1977). The effect of weightloss on plasma and urinary uric acid and lipid levels. Advances in Experimental Medicine and Biology, 76B, 274-277.

Scott, J. T. (1977). Obesity and hyperuricaemia. Clinics in Rheumatic Diseases, 3, 25-35.

Simmonds, H. A. (1967). A method of estimation of uric acid in urine and other body fluids. Clinica Chimica Acta, 15, 375-378.

Taskinen, M. R., and Nikkila, E. A. (1977). Nocturnal hypertriglyceridemia and hyperinsulinaemia following moderate evening intake of alcohol. Acta Medica Scandinavica, 202, 173-177.

Trevaks, G., and Lovell, R. R. H. (1965). Effect of Atromid and its components on uric acid excretion and on gout. Annals of the Rheumatic Diseases, 24, 572-575.

Yano, K., Rhoads, G. G., and Kagan, A. (1977). Epidemiology of serum uric acid among 8,000 Japanese-American men in Hawaii. Journal of Chronic Diseases, 30, 171-184. 